\title{
Research on the Synergy Effect of Cross-border Mergers and Acquisitions in High-tech Enterprises in Shanghai
}

\author{
Yuzhu FENG \\ No.718 Guangming Rd, Pudong New Area,Shanghai,china, \\ fengyuzhu@pudong.gov.cn*
}

Keywords: high-tech enterprises; cross-border M\&A; synergy effect

\begin{abstract}
Currently, the upgrade of the industrial structure in the world provides a great opportunity for cross-border mergers and acquisitions (M\&A) to high-tech enterprises in Shanghai City. At the same time, the status ofigh-tech industry and regional advantages of Shanghai also supply the momentum for M\&A. Therefore, how to improve the M\&A service system for high-tech industries, especially how to effectively play the synergy effect in the whole process of M\&A, becomes the key factor to decide whether cross-border M\&A goes to success or failure.

Currently, Shanghai is building the four centers. Especially, General Secretary Mr. Xi recently indicated that Shanghai shall build into a global innovation center with international influence. However, in order to build into the international innovation center, an extremely important target or a construction standard is to attract and develop a number of the high-tech enterprises with international influence. Apart from developing and growing through independent innovation, a considerably important way is cross-border M\&A. It is a great obstacles placed in front of M\&A companies whether the synergy effect can be achieved through M\&A or not.
\end{abstract}

\section{Analysis on the Environment of Implementing Cross-border M\&A Strategy by}

\section{High-tech Enterprises in Shanghai}

(1) A Great Opportunity Created by the Upgrade of Industrial Structure and Financial Crisis in the World for M\&A

The change and upgrade of the industrial structure in the world provides a good opportunity for the high-tech enterprises in Shanghai to engage in cross-border M\&A. At the beginning of twenty-first Century, the informatization, technicalization and servitization in a high degree of the international industrial structure dominated the adjustment of industrial structure in a new round in the world. With the development of high technology, it will let a number of high-tech industries 
achieve great development. At the same time, it also will make the transformation of traditional industries continue to deepen, which enormously improves the scientific and technological content of manufacturing industry, and thereby advances the quality and efficiency of the world industrial structure. Since the emerging knowledge and technology-intensive industries, especially high technology industry, are the so-called gold-extensive industries, they demand for large funds. High-tech enterprises in Shanghai should seize the opportunity of international industrial adjustment and initiatively become active participants in the international division system through cross-border M\&A.

(2) A Favorable Condition Provided by the Improvement of Domestic Policy and Service Environment for M\&A

The government has improved the policy environment and service environment created by the overseas investment of enterprises. In foreign exchange policy, our country implemented a fixed exchange rate regime for U.S. dollar, which is lack of flexibility, and RMB can not get free convertibility under the capital, which is conducive to absorb foreign capital, prevent capital flight, and ensure the safety of China's foreign exchange reserves. However, it goes against foreign direct investment of our country. In July 21, 2005, our country reformed RMB exchange rate system by upward adjustment of RMB exchange rate, and began to implement a floating exchange rate system based on market supply and demand. In recent years, the continued appreciation of RMB has largely enhanced the purchasing power of the overseas assets by Chinese enterprises. Simultaneously, our country also has gradually relaxed the quantity control of foreign exchange held by individuals and enterprises and time control of foreign exchange settlement and sale.

(3) The Driving Force Supplied by the Status and Regional Advantages of the High-tech Industry in Shanghai for M\&A

Shanghai's high-tech industries play an important role in the whole country. In recent years, Shanghai's high-tech industries have achieved unprecedented rapid development. From 1995 to 2007, output value of high-tech industries in Shanghai grew from 37,807,000,000 RMB to 811,334,000,000 RMB, which increased 21.4 times. In the meantime, the scale of Shanghai's high-tech enterprises constantly expands, and the average total industrial output value per enterprise grows at a rate of $20 \%$ per year. High-tech industries have become an important engine of economic growth in Shanghai as well as an important support for Shanghai to maintain and enhance the international competitiveness. Implementation of cross-border M\&A by Shanghai's high-tech 
industries has obvious regional advantages. First, Shanghai relatively concentrates talents. In recent years, the introduction of high-level personnel in Shanghai grows obviously. At the same time, Shanghai also vigorously promotes the internationalization strategy for talents by improving the ratio of foreign population, which enables to form the internationalization of talents. Second, Shanghai strongly absorbs overseas students for study, making the internationalization of talents' activity space. Third, Shanghai actively carries out the urban personnel export-oriented training to propel the internationalization of local talents.

\section{Analysis on the Synergy Effect of Cross-border M\&A by High-tech Enterprises in} Shanghai-Taking Cross-border M\&A of Shanghai Fosun Pharmaceutical Co., Ltd. as an

\section{Example}

Shanghai Fosun Pharmaceutical (Group) Co., Ltd. (hereinafter referred to as Fosun Pharmaceutical) was established in 1994. Furthermore, it was listed in Shanghai Stock Exchange in August 1998. In October 2012, it was listed in main board of the Stock Exchange of Hong Kong Ltd. It is a public company in the leading position of China's pharmaceutical industry. Fosun Pharmaceutical adheres to the capital M\&A gene of Fusun family, and launches a series of influential movements in M\&A. It also involves in overseas M\&A. For example, in 2009, Fosun Pharmaceutical announced that it purchased $11.18 \%$ shares of Chindex International listed in NASDAQ. In February 2014, it continued to buy 30\% shares of Chindex International. Thereby, Fosun Pharmaceutical completed the acquisition of Chindex International for holdings. In May 2013, Fosun Pharmaceutical declared that it purchased 95.2\% stock equity of an Israeli company-Alma Lasers with $\$ 0.22$ billion USD of transaction amount. From the company's annual financial statements, we can start from management synergy effect, and operating synergy effect to analyze synergy situation after two cases of overseas M\&A by Fosun Pharmaceutical. Meanwhile, since those two cases of overseas M\&A are concentrated in the fields of medical service and medical apparatus and instruments, we also can list the two parts separately from the financial statements for quantitative and qualitative analysis.

We can consider the index of operating synergy effect from the growth rates of operating revenue. 


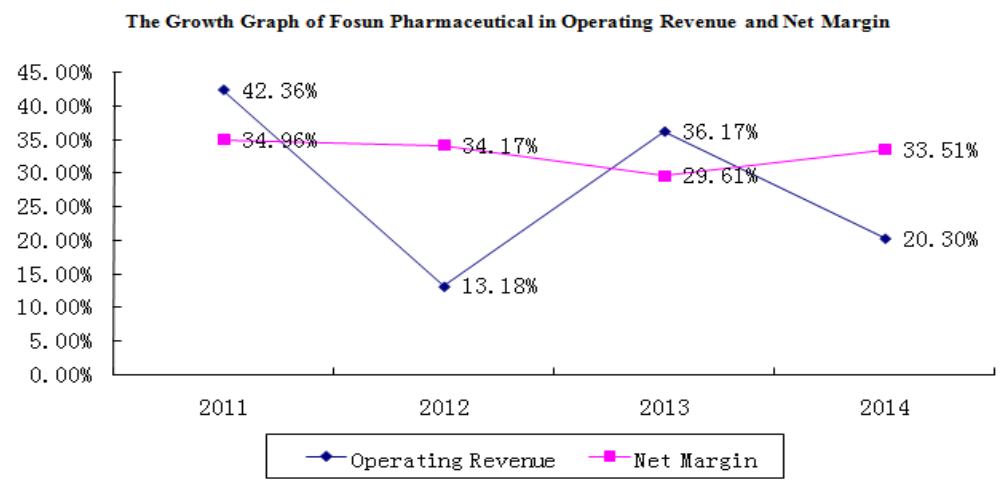

Fig. 1

From the aspect of operating revenue and net margin, we can observe that Fosun Pharmaceutical fluctuates relatively large from 2011 to 2014, but maintains in a growth state. Especially, the net margin of Fosun Pharmaceutical basically maintains at 30\% progressive increase per year.

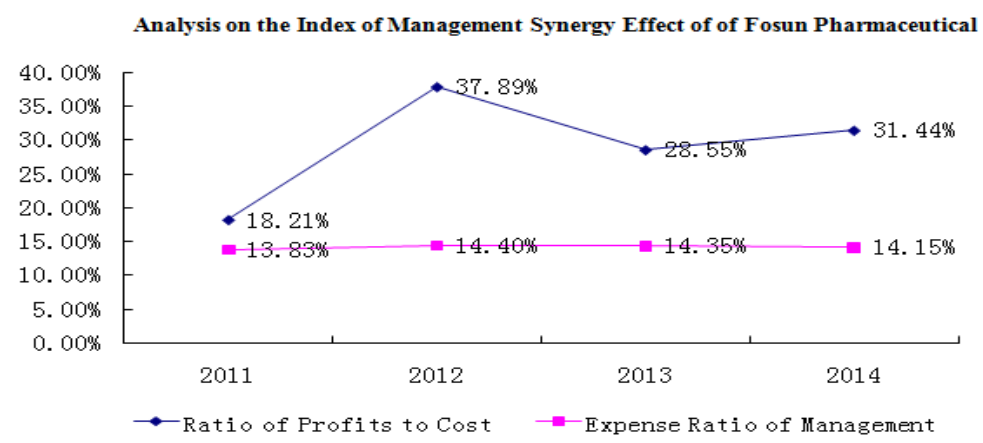

Fig. 2

From the ratio of profits to cost and the expense ratio of management, Fosun Pharmaceutical basically holds in a relatively stable level in every year with the overall growth, showing that the operating result under the operating costs entirely increases and the economic benefits is favorable.

In addition to the analysis of basic financial index, we select the medical services and medical apparatus and instruments from the annual report of Fosun Pharmaceutical, which can largely reflects the efficiency of the two cases of overseas M\&A by the company. 


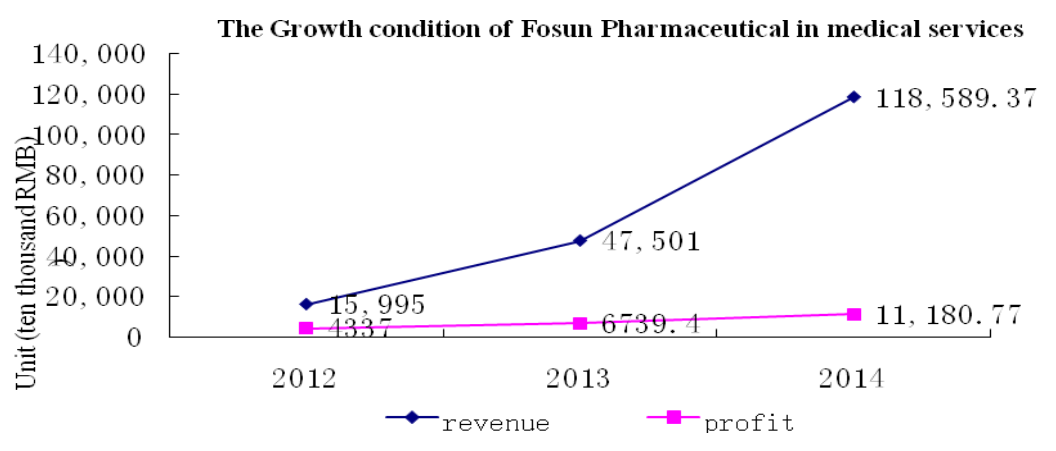

Fig. 3

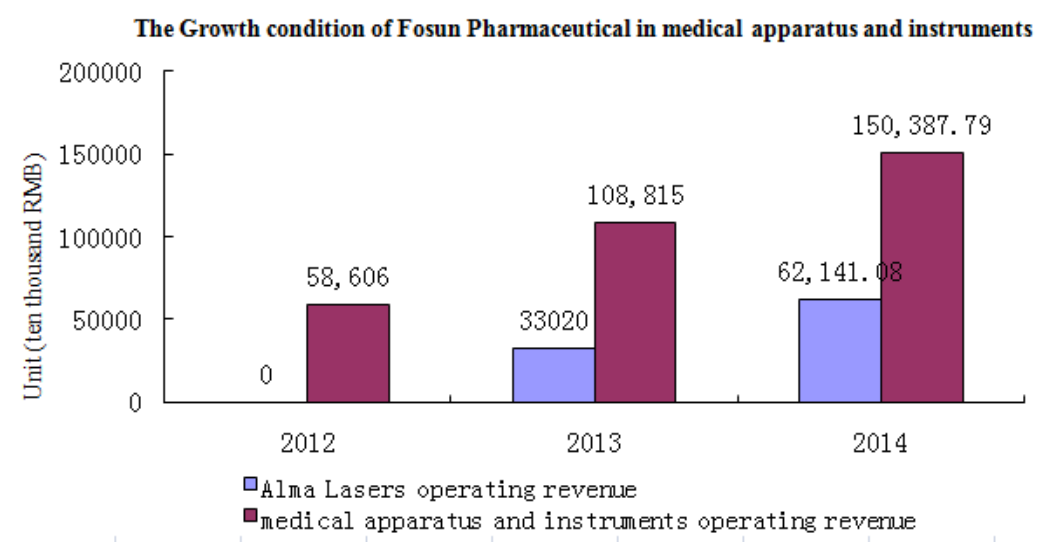

Fig. 4

In order to have a more intuitive, detailed and rigorous analysis on the synergy effect after the M\&A of Chindex International and Alma Lasers by Fosun Pharmaceutical, we can analyze the business growth of the medical service and medical apparatus and instruments which is directly related to M\&A and its synergy effect from the financial statements. From the following two graphs, we can observe in an extremely intuitive way that Fosun Pharmaceutical shows a very good growth ability in the field of the medical service and medical apparatus and instruments after the completion of the two generous cases of overseas M\&A. However, Alma Lasers and United Family indicated an explosive growth ability after the buyout by Fosun Pharmaceutical, of which the operating revenue of Alma Lasers not only rapidly grew (in 2014, it almost doubled), but also its soft power had also been significantly improved. In 2014, there were multiple products which were approved by EU and FDA, indicating that Fosun Pharmaceutical achieved good synergy effects after two cases of M\&A.

3. Suggestions and Measures to Promote the Synergy Effect of Cross-border M\&A in High-tech Enterprises in Shanghai

(1) Sufficient Butt Joint of the Policy Advantage of Shanghai Free Trade Zone 
Under the international background of the sixth global M\&A wave, the construction of free trade zone has brought a new opportunity for the development of Pudong. Moreover, the relevant system reform and policy innovation have provided a strategic opportunity for the implementation of cross-border M\&A for high-tech enterprises. The first is to explore the exchange of investment and financing for facilitation, promote the process of capital account convertibility, further expand the pilot area open to the outside world, and support enterprises to go out. The second is to enlarge the usage of RMB in the cross-border to make enterprises and individuals in Shanghai more flexible in using domestic currency for cross-border transactions, reduce exchange costs, and lower the exchange rate risk. The third is to steadily promote the interest rate liberalization, accelerate the reform process, and support the development of the real economy. The fourth is to deepen the reform of foreign exchange management, further reduce administrative examination and approval, and gradually establish the matched foreign exchange management system.

(2) Construction of a Comprehensive Information Service System to Provide Services for Overseas Investment

The success of overseas M\&A derives from the full-course information service provided by a series of excellent and comprehensive information service organizations for high-tech enterprises. Namely, they supply the search for targets in the initial stage, and offer the analysis on oversea companies and related laws in the middle and later periods, etc., which requires the collaboration between the government and private information service organizations. In other words, the government shall provide certain information service, and also support private information companies in a full range. For example, American government not only provides investors with the information of investment opportunities in developing countries, but also supplies with financial support for the reliability study or the investigation before investment conducted by the tentative technical or financial information relating to the investment plan. The research funds funded by American government are usually 50\% of the investigation cost. Furthermore, American government establishes and sets up overseas embassies and consulates, overseas chamber of commerce, and representatives of the chamber of commerce and industry, to provide information regarding the economy, taxation, investment laws and regulations of investment destination countries. American govenment also provides information services which match with projects through the establishment of Internet platform for docking foreign enterprises.

(3) Vigorous Improvement of the Operational Capacity for Cross-border M\&A in High-tech 
Enterprises in Shanghai

From the perspective of the internal operating procedures of cross-border M\&A, the cross-border M\&A mainly includes three closely related stages, namely, the stage of the strategic option before M\&A, the stage of the negotiation and transaction during M\&A and the stage of the integration after M\&A. The first is to conduct pre-assessments before M\&A and possess with an unequivocal strategy for M\&A. The second is to proceed with multi-channel financing during M\&A to reduce financial and political risks. The cross-border M\&A activities of enterprises will occupy a large amount of working capital, reduce the quick reaction capability and adaptive capacity to environmental changes by enterprises, and increase the risk of business operations. It is recommended that banks and large enterprises can reach an alliance to participate in cross-border M\&A activities, and fight for the support of China's multinational financial institutions in overseas branches. The third is to strengthen the integration after M\&A, pay attention to the construction of technology and the brand. The difference between brand identity and acceptance level bring business integration issues to the Chinese enterprises after cross-border M\&A. Therefore, enterprises should develop a detailed business integration scheme before M\&A, pay attention to the building of brand images, and enhance their brand awareness.

\section{References}

[1] Pei Changhong, Lin Jiang, Cross-border M\&A- a New Form of Utilizing Foreign Investment in China [J], China Industrial Economics, 2007, (1).

[2] Li Shulin, An Analysis on the Strategy for Cross-border M\&A in Chinese Enterprises [J], Economic Forum, 2015, (3).

[3] Li xiu'e, Lu Jinyong, Empirical Research on the Factors Influencing the Efficiency of Cross-border M\&A in Chinese Enterprises Based on the Perspective of the System [J], World Economy Study, 2013, (5).

[4] Bradley, M. and C. Jarrell: Comment, In: J. Coffee, Jr., Lowenstein and S. Rose- Ackerman eds., Knights, raiders and targets [M]; 1988, Oxford University Press, Oxford, Pp. 252-259.

[5] Brouthers, K.D. \& Brouthers, L.E.: Aequisition or green fields tart-up Institutional,cultural and transaction cost influences [J]. Strategic Management Journal, 2000(21), Pp. 89-97. 